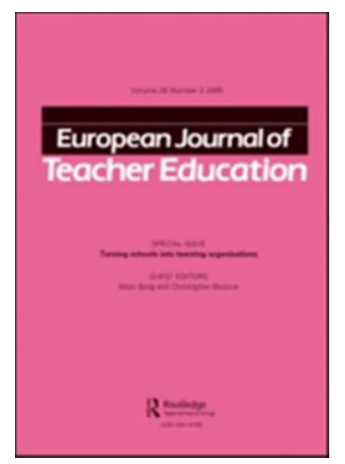

\title{
Ethical dilemmas in senior teacher educators' administrative work
}

\begin{tabular}{|r|l|}
\hline Journal: & European Journal of Teacher Education \\
\hline Manuscript ID & EJTE-2017-0216.R5 \\
\hline Manuscript Type: & Original Article \\
\hline Keywords: & Colleges of Education, Educational Practices, Teacher Educators \\
\hline \multicolumn{2}{|c}{} \\
\hline
\end{tabular}

SCHOLARONE ${ }^{\text {M }}$

Manuscripts 


\title{
Ethical dilemmas in senior teacher educators' administrative work
}

\begin{abstract}
The current study presents the professional experiences of senior teacher educators ('Associate Professors'), with an emphasis placed on ethical dilemmas they face during their administrative work. The main purpose is to characterize the critical incidents underlying these dilemmas, their interpretation, and the ways of balancing the different considerations in their resolution. A qualitative analysis of twelve narrative interviews pointed to four core values which underpinned the approaches taken by teacher educators in their handling of critical situations: perception of integrity, empathy and care, commitment to the institution, and the need to promote initiatives. Findings indicate that the concept of integrity is central to the these educators' decision making processes, but that this concept is interpreted differently according to the personality characteristics, experience, and educational vision of the interviewees. It is proposed to conduct further studies that examine the interpretation of 'integrity' as a concept among senior teacher educators and the manner in which it emerges in their professional lives.
\end{abstract}

Keywords: ethical dilemma, teacher educators, administration

\section{Introduction}

Senior teacher educators, who are the focus of this study, constitute a unique professional group who need to demonstrate competence across a wide arc of domains that includes for example, teaching and guiding students, research and writing, leading professional committees, administering academic programs and managing faculty staff (Griffiths , Thompson \& Hryniewicz, 2014; Murray, 2015). Naturally, teacher educators deal with a multiplicity of issues on a daily basis and are required to make decisions across this spectrum of areas. They must balance between human tendencies, emotions, instincts, personal interests, and socially acceptable behaviors, and at the same time, serve as a personal example of morality and justice for future generations of teachers. However, according to latest empirical studies (Edling \& 
Mooney Simmie, 2015; Shapira-Lishchinsky, 2011), the decision makers are not always aware of the ethical implications of various situations and the essence of the concept of ethics in practice. This situation leads to a need for stimulating discourse in the research literature.

The current study seeks to explore the most common ethical dilemmas faced by senior teacher educators who serve at teaching training colleges in Israel as part of their administrative work. The main aim is to map these dilemmas according to three axes (Cianci, Hannah, Roberts \& Tsakumis, 2014): (a) the critical incidents and sensitive events in the professional lives of senior teacher educators that lead them to cope with ethical dilemmas; (b) the way they interpret these dilemmas in order to arrive at the optimal solution, (c) the balance between objective and subjective considerations, and the issues that were placed on the scales in these dilemmas.

\section{Critical Dilemmas and Seniority}

Ethical dilemmas can be defined as an internal dialogue of the individual regarding two alternatives to solving a problem, with each alternative consisting of both advantages and disadvantages (Edling \& Mooney Simmie, 2015; ShapiraLishchinsky, 2009). According to Bukor (2015), the manner in which decisions are made around such dilemmas is a function of personal beliefs, perceptions, life wisdom and especially professional experience. The other authors (Edling \& Mooney Simmie, 2015; Pereira, Lopes \& Marta, 2015; Strom, Abrams \& Tammy, 2016) claim, as a supporting argument, that while the novices' work routines are characterized by a state of "incessant indecision" which is caused by ongoing interaction with different professional groups, and sometimes is accompanied by conflicts of interest, the seniors are expected to exhibit a clear agenda for problem resolution while 
overbalancing between different alternatives of the problematic issue. Thus, since dilemmas may occur simultaneously across a wide range of activities, the manner in which they are decided is determined not only by the professional self-concept, but also, primarily, by environmental and contextual constraints, professional experience and seniority (Langlois \& Lapointe, 2007; Shapira-Lishchinsky \& Rosenblatt, 2010).

\section{Critical Incidents and Ethical Tensions}

The literature on ethics in education (Murphy, Pinnegar \& Pinnegar, 2011; Pillen, Beijaard \& Brok, 2013; Shapira-Lishchinsky, 2009) refers primarily to "tensions" between an individual and his/her environment in the workplace, in order to balance the formal issues (such as institutional rules, academic standards) and informal issues (related to climate maintenance in the institution and human relations with students and staff to which the individual belongs). Therefore, while the formal issues refer to aspiring to a high level of professionalism in the teaching area and compliance with the institution's policies, the informal issues draw attention to the social and emotional needs of the individual (Ehrich et al., 2011; Johns, McGrath \& Mathur, 2008; Norberg \& Johansson, 2007; Pope et al., 2009; Rogers \& Sizer, 2010). According to researchers (Campbell, 2004; Sumsion, 2000; Zipin \& Brennan, 2006), such tensions can arise when a teacher is faced with a decision about how to respond to critical situations and how to communicate this decision to colleagues or students. For example, when a colleague is in breach of the rules or acting in a manner which is counter to the culture of the institute, in relation to his or her professional conduct or in his/her interaction with students, the senior staff member is faced with an ethical dilemma that requires $\mathrm{him} / \mathrm{her}$ to set priorities, and to respond in a manner that will provide an optimal solution to the issue (Pereira et al., 2015 ). 
These ethical dilemmas illustrate the complexity of the day-to-day activities of teacher educators who serve in administrative positions at their institutions. Shapiro and Stefkovich (2016) offer a model of real-life ethical dilemmas based on the objective observation of the educational reality of senior teacher educators' work, which is divided into four paradigms: the ethics of justice, the ethics of critique, the ethics of caring and empathy, and the ethics of professionalism. The current research presents these and other issues, which are reflected in the work of associate professors in teacher training colleges, whose work culture is significantly different from other professional sectors, but which is saturated with various ethical dilemmas such as the ones mentioned above.

\section{Senior Teacher Educators}

Academic faculty members who work in teacher education colleges, also known as "teacher educators", constitute a unique professional group that is required to combine simultaneously many areas of activity: teaching, promoting professional initiatives and holding academic administrative roles. Besides that, their uniqueness expresses itself in the fact that their professional identity lies on the "seam line" between a "teacher" in the education system and a "lecturer" in an institution of higher education. In contrast to the last references which examined the educational aspects of ethics (Sumsion, 2000; Zipin \& Brennan, 2006), such as caring and empowering preservice teachers, the present study is interested in exploring ethical issues from the perspective of tasks and experiences in the field of administration and team leadership, due to two reasons. Firstly, this is primarily due to the lack of research on the ethics of educational leadership and administration for this group. And secondly, the above arguments point to the importance of examining such issues for the professional group that stands at the top of the teacher training pyramid and is 
expected to serve as role models to the future generation of educators (Edling \& Mooney Simmie, 2015; Opazo, Aramburuzabala \& García-Peinado, 2014; Shagrir, 2015).

\section{Methodology}

The current study was conducted by using a qualitative-narrative approach (Clandin, 2016) based on professors' life stories concerning the ethical dilemmas they have dealt with, the considerations that were pivotal in their solution, and their interpretations of unique events that gave rise to these dilemmas. This research methodology allows for the exploration of authentic situations, tensions and dilemmas that characterize the human decisions and actions by focusing on the special characteristics of a unique professional group (Shkedi, 2011). According to this approach, the open-ended questions should be formulated in a way that directs the interviewees to share a life story with respect to the following elements: (a) orientation - time, place, context; (b) sequence of events that preceded before or during the presented situation; (c) complexity and sensitivity to the current dilemma; (d) an assessment of the importance, meaning and implications of the alternative solutions and modes of actions; (e) the end of the story - how the dilemma was decided and what were the accompanying considerations for this decision.

\section{Sample}

Twelve associate professors from five Israeli teaching training colleges served as a sample. The participants were selected by using the purpose-oriented criterion method, according to predefined criteria, in line with the theory underlying the research framework (Patton, 2002). In this case, the sample selection was based on the following three criteria: (a) seniority (associated professor for two years or more), (b) 
experience in teacher education (15 years or more); (c) experience in academic administrative position (4 years or more), as is presented in Table 1. I adhered to these criteria in order to allow the interviewee to reflectively interpret the professional challenges and dilemmas based on long-term seniority and experience (Clandin, 2016).

\section{Procedure}

Semi-structured interviews were conducted, and were based on a 'written topic guide' with general issues for conversation. This procedure allowed the interviewee to provide authentic life stories, with the possibility of raising spontaneous issues linked to the story according to its development (Shkedi, 2011). In hindsight, the narrative approach assisted the interviewees in sharing their professional experiences, while allowing them to reflect on ethical dilemmas they had encountered, their emotional reactions, deliberations, and beliefs regarding their situations. The interview guide was constructed in four sections: (a) questions related to the current career stage, main professional experiences and tasks; (b) stories and examples of the critical incidents and ethical tensions with which the interviewee has recently experienced; (c) presenting the essence of the dilemma (the strengths and weaknesses of each alternative) and the deliberations engaged in, (d) the manner in which the dilemmas were dealt with, the interviewees' professional views, and the reasons that ultimately lead to the preferred resolution.

To examine the validity of the intended tool, I conducted a pilot interview with one of my colleagues who had the same characteristics as the sample group, and following the pilot I revised my questions (Marshall \& Rossman, 2011). At the beginning of the interview, an overview of the interview schedule was presented, and 
the interviewees signed a form of consent. The transcriptions of each interview served as a "raw data base" (Shkedi, 2011) that were processed by recognizing the main themes underpinning the basis of each dilemma discussed, as well as identifying the common words and phrases that occurred. This method enabled me to identify similarities in a manner that would generate common focal points, in order to reach conceptual generalization and to draw a model of prevalent ethical dilemmas among this professional group.

\section{Findings}

Based on the interviewees' testimonies, ethical dilemmas are pervasive in their daily routines, requiring them to decide on priorities and to reevaluate their fundamental values when interacting with colleagues. The findings presented the main characteristics of these dilemmas, perceptions, approaches, and considerations for decision-making. A qualitative analysis of the twelve narratives led me to outline four core values that constitute the foundations of their (in) decisions during critical incidents and ethical tensions: (1) perception of integrity; (2) empathy and care; (3) commitment to the institution; and (4) the need to promote initiatives. The testimonies presented by the interviewees indicated a tension between the perception of integrity and the three other core values, and thus the findings are presented in terms of these three distinctions: (a) perception of integrity vs. empathy and care; (b) perception of integrity vs. commitment to the institution; (c) perception of integrity vs. promotion of initiatives.

\section{Perception of Integrity vs. Empathy and Care}

A large part of the issues raised in the interviews concerned the decision between emotion and common sense, which includes the issues of transparency and the 
appropriate way to share with colleagues what is going on in the institution, especially in situations of conflict and anxiety. In this section, conflicting evidence was heard regarding the need for transparency in the sharing of information with staff even in cases where it may create negative consequences for the individuals in their professional environment, and may disrupt their sense of wellbeing and confidence. The example is illustrated below by Prof. D.

There are many faculty members who come and ask me what would happen to them in future. Everyone is worried about the [...] (organizational reform). Could they survive it? Many (administrators) are vague, do not provide information. I try my best to be honest and to respond transparently. Even if that means the colleague will not love the answer.

Another example raised the need to engage with sincerity and clarity, even if this was unpopular with more junior faculty members. Thus for example, Prof. M. summed up his approach by saying: "I have to choose my battles".

In such a senior and leading position like mine, the dilemmas are constantly present. You cannot run away from them. And one of the things you need to know when you get a high position is that you will create enemies for you. There's nothing to do. I try to be the most human in the world. But if there is no choice, if that is good for the college, if faculty and department require it, I will allow that person not to love me for several years.

This approach was supported by an incident from his professional experiences:

A well-known lecturer in Israel worked here. He really did a good job, my good colleague; I collaborate with him a lot. But now he has reached retirement age (65) and he should retire. And he doesn't want to retire. This person comes to me and says: How is that? It cannot be. And he sees that I'm not fighting for him. Because it is obvious that if I am dean of faculty then I can fix it for him. But it's wrong for me to 
fight for it. And I cannot tell him why. I have to make a very strong introspection of what I'm fighting for and what I'm not fighting for. If integrity makes me walk with my head against the wall all the time - I'm really not smart! You have to go a lot around! You have no choice!

Prof. N. added her own example to a similar situation.

There is no doubt that between friendships I have built here for many years and the needs of the institution there is sometimes a very large gap. And I had an excellent friend who was a respected teacher and was a beloved pedagogical instructor, but she did not fit the system as she had no doctorate. Although she contributed greatly to the college and the students, she did not meet the requirements of the Council for Higher Education and I had to part ways with her.

\section{Perception of Integrity vs. Commitment to the Institution}

This issue is intended to reflect a situation in which the need for moral behavior that is consistent with the individual's beliefs collides with professional commitment to the institution, the need to maintain a positive climate, good relations with colleagues and senior administration, and the desire to demonstrate a responsible administrative approach. Prof. O reflected on this dilemma as follows:

To pretend to be in favor of industrial quiet, to cooperate with unpleasant people in favor of an important initiative, if it's right for the college, then, yes, sure.

In support of the statement, the following 'example of tension' was shared:

I have a lecturer in the faculty who is simply a catastrophe in terms of human relations. And both the students and the staff members really feel it! But she is very strong in her field, and she represents the faculty and the college well at international conferences and in publications. So the question is what is right to do. To change it I will not succeed because she is very stubborn. So I do think very strongly which tasks and which courses are suitable to give her. 
Prof. K presented his approach to manage dilemmas of this kind:

\begin{abstract}
When you work with people, you have to place scales on your table and weigh the pluses. If I think the plus is significant and I can build a system that will moderate the minuses, I ask myself - how many potential lecturers do I have in the field who are good? The conclusion is clear. All the time one has to look for compromises, to straighten out holes and sacrifice certain areas in order to empower others. That's the essence of the job.
\end{abstract}

According to Prof. E, his involvement in the policy-making committees at the college often requires him to "recalculate" his perception of integrity against commitment to the institutional committees/processes and solidarity with its members. This is what he says:

During my work I saw all the preoccupation of the appointments/tenure committees with politics, such as who to promote or what criteria to use, often not very objective. Subjective considerations such as collegiality and cooperation were often considered. There were a few cases where the committee I sat on decided not to give tenure or even to dismiss for practical reasons people I worked with and knew well. Although there are ostensibly practical reasons in any case, it is difficult to fire a person and vote in favor of not giving him tenure. But sometimes there is no choice. So in the end I voted with everyone but felt uncomfortable. And if the vote was secret I might have avoided it. There is also the interest and the good of the college to consider.

Finally, Prof. B shared ethical issues with which she contends on a daily basis in her work:

Our institution is recognized as a very pluralistic and multicultural college; and we espouse a vision of openness and egalitarianism, which sometimes expresses itself in affirmative action. And then I am a bit torn between the need for equality and justice and the needs of many faculty members here. This leads me to dilemmas during certain decisions. And ethically I decided that I was taking the best people, in 
terms of teaching ability and an expertise in a particular subject. This is the correct decision, for my opinion. I am definitely against discrimination of any kind, and also against affirmative action. If I have two people who vary in their abilities, I will take the best one and only him.

\section{Perception of Integrity vs. Promotion of Initiatives}

During the conversation, the interviewees raised the issues of the moral aspect of the way to lead academic or educational initiatives. Prof. A., whose main focus is on educational-cultural activity, said that this challenge forces him to look in the 'mirror', and re-examine his priorities against the scale of values.

I ask myself, for example, how willing I am to cooperate with people whom I identify as my political enemies. But if I want them to help me, I must cooperate with them. That is it, not to be a fanatic, and to choose my wars. On the other hand, there are also dilemmas that I would not agree with. For example, If I'm supposed to go to a familiar figure and ask her to make a donation to an event I hold, after hearing her speak sharply about education and society, this is a serious dilemma. If I cooperate with her, I cannot make statements against her. Like a person who markets health food but whose main contribution is from Coca-Cola. In that case-l give it up. It is clear.

Prof. D summed up these types of dilemmas in the following manner:

A solution to everything is finding the boundaries and how much I am willing to compromise to achieve certain accomplishments. This is authenticity, a unity between the external and internal parts of a person. I desire to stand straight with a clear road ahead in order to allow people to trust me. I am not an opportunist. Not to be manipulative. It is important to be honest with yourself and with others.

Prof. L. described the ethical dilemma that typifies the spirit of the college as part of the process of change that the institution often undergoes: 
In fact, we are perceived as a leading college in implementing educational innovations and reforms which the Ministry of Education conveys to colleges as an important goal. This is where we would love to stay. But when you reach the stage where you need to lead change, you must know how to do it in a way that will recruit partners who will be by your side in this change. You cannot do it alone! And you also cannot sow panic over team players. The main question is when and how you give over the information to all members. It is the art of management and team leading.

The sensitive moments, the manner in which the administrator interprets the context and reaches an optimal solution, that supports the "sustainability" factor required to continue stimulating new initiatives in the college were described by Prof. L. in the follow way:

I happened to hear complaints from people like: "They think we have a mobile identity! We must change it in accordance with the constantly changing Ministry of Education's agenda". Then I said: "We will do that without losing our identity. First, we will reveal to all exactly who we are and then determine what prices we are willing to pay if we go ahead with any reform. And if there are essential things for us, such as our integrity and our mission; we will not give them up. We will try talking to them and reaching compromises". What also gave me strength is the PR they (the Ministry of Education) made for us. All can see the model we developed on the subject of cooperation between academia and the educational field. And it is noted that we were the pioneers to do so! They see us as experts in creating partnerships, so we will continue to strengthen it, because it is our power.

In conclusion, it should be noted that there is a certain degree of polarization in the testimonies of teacher educators in this study. Some of them emphasize the need for transparency in front of staff members, sincerity and the sharing of a picture in its entirety. Others argue that they must exercise great caution, and sacrifice certain areas in order to empower others in an institution where they work. 


\section{Discussion}

The current study attempted to examine the ethical dilemmas in the professional lives of senior teacher educators, and the way it come to the forefront in the administrational, interpersonal, cultural and political aspects of their work. The totality of these dilemmas, critical incidents, and examples of tension that underlie them, allowed me to generate a conceptual framework for the issue under discussion and to present core values, reflected in the testimonies of senior educators, in a polarized manner where they are pitched against their commitment to integrity. The findings provide a new perspective in terms of four core values and the interaction between them: perception of integrity, empathy and care, commitment to the institution, the need to promote initiatives. The cross-referencing of common terms that appeared in the professors' testimonies, their contextual characteristics, and the interpretations to justify the resolution of these dilemmas as tending to one side or another, presented a division of these core values into sub-definitions. The perception of integrity, which was discovered as a main core value, is associated with the concepts of honesty, fair use of authority, responsibility, transparency, sincerity, and clarity. The second core value, 'commitment to the institution', is described as a compliance with procedures and work regulations at the administrative level, and as a convention to create a positive organizational climate, a pleasant relationship with colleagues, and to stabilize the image of a responsible administrator and leader who represents the institution faithfully. The third core value, 'the need to promote initiatives' was reflected in educational, cultural and academic activities and to assess future prospects for realizing all these aspirations and initiatives. Finally, the fourth core value, 'empathy and care', refers to ensuring a sense of security, well-being, welfare, and dignity towards staff members (Graph 1). 
According to the literature review (Langlois \& Lapointe, 2007; Leroy, Palanski, \& Simons, 2012; Norberg \& Johansson, 2007; Thiel et al., 2012) ethical behavior is the one that neutralizes personal needs, preferences, motivations and desires, and demonstrates the balancing process that expresses the analysis of the existing situation and of the contextual circumstances (social, cultural and personal) before making decisions. In this process the individual must examine creative solutions that will help to reach an optimal balance - the desired outcome with the moral price that will be charged. It must also exercise "self-regulation" which shows that it is guided by clear internal ethical standards, and as a result, behaviors and decisions are consistent with its internal values.

An interesting distinction was argued in the professional literature (Bullough, 2011) dealing with the experience and perception of ethics among school teachers, according to which their interpretation of the concept of ethics is expressed in a variety of behaviors related to professional commitment and compatibility with school culture and work practices. Alongside this is the neglect and blurring of other significant values in ethics, such as morality, humanity, justice and recognition of the diversity of students (Macfarlane, 2004). Unlike the previous research, the teacher educators who participated in this study do not avoid managing the ethical dilemmas. At the same time, they explain their pattern of behavior in that the existing problem is not significant enough to create a storm in the environment, and that the current situation has a relative advantage, and that the increased preoccupation with it may harm the social climate and the sense of solidarity with colleagues. It was noted that the interviewees felt free to openly discuss their ethical dilemmas and tensions in an attempt to outline principles for solving similar problems and to advance their solution. 
The phenomenon of tensions in the work of teacher educators has been discussed extensively in the academic literature (Flores, 2018; Griffiths, Thompson \& Hryniewicz, 2014; Tack et al., 2018; Yamin-Ali, 2018). It has been studied in the context of teacher educators' professional development, emotional needs, collegial aspects, and expectations of the institution. For example, researchers (Flores, 2018; Tach et al., 2018) relate to the existence of tension between the complexity of the professional identity of teachers' educators and their need to make their work more visible and explicit to colleagues and to establish their professional status. The other researchers (Griffiths, Thompson \& Hryniewicz, 2014) argue that the tensions between cultivating a pedagogical professional identity, professional autonomy, commitment to teamwork, and loyalty to the academic institution, create difficulties in professional integration. These issues, which were mentioned in the context of teacher educators in early and mid-career stages, are consistent with the findings of this study, which deals with senior teacher educators in their later career, whose professional identity as administrators is linked to integrity. Ethical dilemmas, which are explained by conflict between them and their commitment to the institution, their responsibility to demonstrate empathy and care for those around them, and the need to raise their status by promoting initiatives, and the desire to make their leadership meaningful and visible, undoubtedly contributes to the complexity of this professional group.

In regard to the division into the three types of ethical dilemmas presented in the findings section, a number of conclusions can be drawn. First, there is a tendency among the interviewees to adhere decisively to the concept of integrity, especially when they have to decide between this approach and the opportunity to promote initiatives. On the other hand, the perception of integrity is of secondary importance 
in cases where professional values, such as commitment to the institution, are at stake. It is possible that the situation arose out of the teacher educators' clear need to lead changes and empower staff at the institution in keeping with its culture (Griffiths, Thompson \& Hryniewicz, 2014). Regarding the dilemma of empathy and caring visà-vis the concept of integrity, the respondents do not make a clear decision, and the examples of the cases provided by them show a great variety of ambivalent considerations. It is possible that ambiguity in this area stems from the fact that coping with these dilemmas depends on a variety of personal, professional and cultural aspects (Yamin-Ali, 2018). This distinction calls for the need for in-depth research to learn in a fundamental way about integrity and how it is reflected in the professional lives of senior teacher educators. Another conclusion that emerges from the stories and interpretations of teacher educators is their tendency to demonstrate a clear agenda and to formulate administrative principles for dealing with similar dilemmas in the future. Teacher educators interpreted the incidences and the cases of tension experienced, as opportunities to learn and to address important issues.

These conclusions, which emphasize the place of common core values in the work of an administrator in a teacher training institution, accurately reflect the daily challenges of diverse professional groups in the field of education. Their interpretation may also contribute to other aspects of teacher education, including the conceptualization of instructing student teachers to deal with sensitive tensions which are likely to arise during their teaching and work in schools (De Neve \& Devos, 2017; Flores, 2017). The present study is a 'spearhead study' of the ethical dilemmas expressed in the administrative work of senior teacher educators, a subject that remains in the shadows, probably due to the sensitivity of the issue, the complexity of this professional group, the difficulty in accessing it, and the challenge of 
implementing of these findings. The relationship between an educational vision of an individual and his/her style when dealing with ethical dilemmas, which was discussed here, is one that requires further research, particularly where the leaders are also in the field of teacher education,. Finally, the research provides initial insights with an emphasis on the ethical issues facing teacher educators when they are required to make managerial and organizational decisions, thus creating an opportunity to interrogate the concept of integrity. It is evident that this is a rich seam of future research in the field of higher education and academic administration.

\section{References}

Bullough, R. V. (2011). Ethical and moral matters in teaching and teacher education. Teaching and Teacher Education, 27(1), 21-28.

Campbell, E. (2004). Ethical considerations of collegial loyalty as a one view of teacher professionalism. Teachers and Teaching: Theory and Practice, 2, 191-208.

Cianci, A. M., Hannah, S. T., Roberts, R. P., \& Tsakumis, G. T. (2014). The effects of authentic leadership on followers' ethical decision-making in the face of temptation: An experimental study. The Leadership Quarterly, 25(3), 581-594.

Clandinin, D. J. (2016). Engaging in narrative inquiry. Routledge

De Neve, D., \& Devos, G. (2017). Psychological states and working conditions buffer beginning teachers' intention to leave the job. European Journal of Teacher Education, 40(1), 6-27.

Edling, S., \& Mooney Simmie, G. (2015). (Re) positioning the Democratic (Ethical) Identity of the Teacher Educator within Global Policy Discourses of Compliance. In 
AERA [American Educational Research Organization] 2015 Annual Meeting, Chicago, Illinois, April 16-20, 2015.

Edling, S., \& Mooney Simmie, G. (2014). The changing democratic (ethical) dimension in Teacher Educator's professional identity?: A comparative critical discourse analysis of policy documents regarding teacher educator's democratic (ethical) identity in the Republic of Ireland and Sweden. European Journal of Teacher Education.

Ehrich, L. C., Kimber, M., Millwater, J., \& Cranston, N. (2011). Ethical dilemmas: A model to understand teacher practice. Teachers and Teaching: Theory and Practice, $17(2), 173-185$.

Flores, M. A. (2017). Editorial. The complexities and challenges of be (com) ing a teacher and a teacher educator, European Journal of Teacher Education, 40(1), 2-5.

Flores, M. A. (2018).Editorial. Tensions and possibilities in teacher educators' roles and professional development. European Journal of Teacher Education, 41(1), 1-3.

Griffiths, V., Thompson, S., \& Hryniewicz, L. (2014). Landmarks in the professional and academic development of mid-career teacher educators. European journal of teacher education, 37(1), 74-90.

Johns, B.H., McGrath, M.Z., \& Mathur, S.R. (2008). Ethical dilemmas in education: Standing up for honesty and integrity. Lanham, MD: Rowman \& Littlefield.

Langlois, L., \& Lapointe, C. (2007). Ethical leadership in Canadian school organizations: Tensions and possibilities. Educational Management Administration \& Leadership, 35(2), 247-260. 
Leroy, H., Palanski, M. E., \& Simons, T. (2012). Authentic leadership and behavioral integrity as drivers of follower commitment and performance. Journal of Business Ethics, 107(3), 255-264.

Macfarlane, B. (2004). Teaching with integrity: the ethics of higher education practice. London: Routledge-Falmer.

Marshall, C., \& Rossman, G. (2011). Designing qualitative research (2nd ed.). Thousand Oaks, CA: Sage.

Murphy, M. S., Pinnegar, E., \& Pinnegar, S. (2011). Exploring ethical tensions on the path to becoming a teacher. Teacher Education Quarterly, 38(4), 97-113.

Murray, J. (2015). Teacher education and higher education. Teacher Education in Times of Change, 179.

Norberg, K., \& Johansson, O. (2007). Ethical dilemmas of Swedish school leaders. Educational Management Administration \& Leadership, 35(2), 277-294.

Opazo, H., Aramburuzabala, P., \& García-Peinado, R. (2014). Service-Learning methodology as a tool of ethical development: Reflections from the university experience. AISHE-J: The All Ireland Journal of Teaching and Learning in Higher Education, 6(1).

Patton, M.Q. (2002). Qualitative research \& evaluation methods (3rd ed.). Thousand Oaks, CA: Sage Publications.

Pereira, F., Lopes, A., \& Marta, M. (2015). Being a teacher educator: professional identities and conceptions of professional education. Educational research, 57(4), 451-469. 
Pillen, M., Beijaard, D., \& Brok, P. D. (2013). Tensions in beginning teachers' professional identity development, accompanying feelings and coping strategies. European Journal of Teacher Education, 36(3), 240-260.

Pope, N., Green, S.K., Johnson, R.L., \& Mitchelle, M. (2009). Examining teacher ethical dilemmas in classroom assessment. Teaching and Teacher Education, 25, 778782.

Rogers, L., Sizer, N. Faust. (2010). Ethical dilemmas in education: Standing up for honesty and integrity. Journal of Moral Education, 39(2), 243-248.

Shagrir, L. (2015). Working with students in higher education-professional conceptions of teacher educators. Teaching in Higher Education, 20(8), 783-794.

Shapira-Lishchinsky, O. (2009). Towards professionalism: Ethical perspectives of Israeli teachers. European Journal of Teacher Education, 32(4), 473-487.

Shapira-Lishchinsky, O., \& Rosenblatt, Z. (2010). School ethical climate and teachers' voluntary absence. Journal of Educational Administration, 48(2), 164-181.

Shapira-Lishchinsky, O. (2011). Teachers' critical incidents: Ethical dilemmas in teaching practice. Teaching and Teacher Education, 27(3), 648-656.

Shapiro, J. P., \& Stefkovich, J. A. (2016). Ethical leadership and decision making in education: Applying theoretical perspectives to complex dilemmas. Routledge.

Shkedi, A. (2011). The meaning behind the words: Methodologies of qualitative research: Theory and practice. Tel Aviv: Ramot (In Hebrew). 
Strom, K. J., Abrams, L., \& Tammy Mills, C. D. (2016). “I, Teacher Educator": Grappling with ethical responsibility, hybrid pedagogies, and neoliberal agendas in mangled educational spaces. Enacting self-study as methodology for professional inquiry, 53.

Sumsion, J. (2000). Caring and empowerment: A teacher educator's reflection on an ethical dilemma. Teaching in Higher Education, 5(2), 167-179.

Tack, H., Valcke, M., Rots, I., Struyven, K., \& Vanderlinde, R. (2018). Uncovering a hidden professional agenda for teacher educators: A mixed method study on Flemish teacher educators and their professional development. European Journal of Teacher Education, 41(1), 86-104.

Thiel, C. E., Bagdasarov, Z., Harkrider, L., Johnson, J. F., \& Mumford, M. D. (2012). Leader ethical decision-making in organizations: Strategies for sensemaking. Journal of Business Ethics, 107(1), 49-64.

Zipin, L., \& Brennan, M. (2006). Meeting Literacy Needs of Pre-service Cohorts: Ethical dilemmas for socially just teacher educators. Asia-Pacific Journal of Teacher Education, 34(3), 333-351.

Yamin-Ali, J. (2018). Tensions in the work context of teacher educators in a School of Education in Trinidad and Tobago: a case study. European Journal of Teacher Education, 41(1), 66-85. 
Table 1: The Sample Data

\begin{tabular}{|c|c|c|c|c|c|c|c|c|c|}
\hline \multirow[t]{2}{*}{ \# } & \multirow{2}{*}{$\begin{array}{l}\text { Pen } \\
\text { Name }\end{array}$} & \multirow[t]{2}{*}{ Age } & \multirow[t]{2}{*}{ Gender } & \multirow{2}{*}{$\begin{array}{l}\text { College } \\
\text { Location }\end{array}$} & \multirow[t]{2}{*}{ Position } & \multicolumn{4}{|c|}{ Period of } \\
\hline & & & & & & $\begin{array}{c}\text { Professorship } \\
\text { (years) }\end{array}$ & $\begin{array}{l}\text { Holding } \\
\text { the } \\
\text { position } \\
\text { (years) }\end{array}$ & $\begin{array}{l}\text { Working } \\
\text { in the } \\
\text { college } \\
\text { (years) }\end{array}$ & $\begin{array}{c}\text { Teacher } \\
\text { educating } \\
\text { (years) }\end{array}$ \\
\hline 1 & $\begin{array}{c}\text { Prof. } \\
\text { A }\end{array}$ & 61 & M & Center & $\begin{array}{l}\text { Head of } \\
\text { Chair }\end{array}$ & 8 & 4 & 30 & 30 \\
\hline 2 & $\begin{array}{c}\text { Prof. } \\
\text { D }\end{array}$ & 55 & $F$ & Center & $\begin{array}{l}\text { Dean of } \\
\text { Facility }\end{array}$ & 6 & 4 & 22 & 24 \\
\hline 3 & $\begin{array}{c}\text { Prof. } \\
\text { G }\end{array}$ & 67 & $M$ & Center & $\begin{array}{l}\text { Head of } \\
\text { Research } \\
\text { Authority }\end{array}$ & 6 & 2 & 24 & 24 \\
\hline 4 & $\begin{array}{c}\text { Prof. } \\
\mathrm{O}\end{array}$ & 65 & $\bar{M}$ & Center & $\begin{array}{l}\text { Dean of } \\
\text { Facility }\end{array}$ & 18 & 4 & 4 & 32 \\
\hline 5 & $\begin{array}{c}\text { Prof. } \\
\text { L }\end{array}$ & 62 & $F$ & Center & $\begin{array}{l}\text { Dean of } \\
\text { Facility }\end{array}$ & 15 & 3 & 15 & 15 \\
\hline 6 & $\begin{array}{c}\text { Prof. } \\
\text { P }\end{array}$ & 62 & $\mathrm{~F}$ & Center & $\begin{array}{l}\text { Head of } \\
\text { MA } \\
\text { program }\end{array}$ & 6 & 4 & 30 & 30 \\
\hline 7 & $\begin{array}{c}\text { Prof. } \\
T\end{array}$ & 58 & $M$ & South & $\begin{array}{l}\text { Head of } \\
\text { Research } \\
\text { Authority }\end{array}$ & 8 & 4 & 22 & 22 \\
\hline 8 & $\begin{array}{c}\text { Prof. } \\
\text { M }\end{array}$ & 65 & $\mathrm{~F}$ & North & $\begin{array}{l}\text { Head of } \\
\text { MA } \\
\text { program }\end{array}$ & 4 & 4 & 4 & 16 \\
\hline 9 & $\begin{array}{c}\text { Prof. } \\
\text { R }\end{array}$ & 65 & $M$ & Jer. & $\begin{array}{l}\text { Head of } \\
\text { MA } \\
\text { program }\end{array}$ & 7 & 7 & 7 & 28 \\
\hline 10 & $\begin{array}{c}\text { Prof. } \\
S\end{array}$ & 57 & $\bar{M}$ & Center & $\begin{array}{l}\text { Head of } \\
\text { school }\end{array}$ & 8 & 2 & 2 & 23 \\
\hline 11 & $\begin{array}{c}\text { Prof. } \\
\mathrm{K}\end{array}$ & 68 & $\mathrm{M}$ & Center & $\begin{array}{l}\text { Head of } \\
\text { Program }\end{array}$ & 15 & 3 & 30 & 30 \\
\hline 12 & $\begin{array}{c}\text { Prof. } \\
\text { B }\end{array}$ & 66 & $F$ & Center & $\begin{array}{l}\text { Dean of } \\
\text { Facility }\end{array}$ & 7 & 4 & 32 & 32 \\
\hline
\end{tabular}


Graph 1: Four Core Values of Ethical Dilemmas

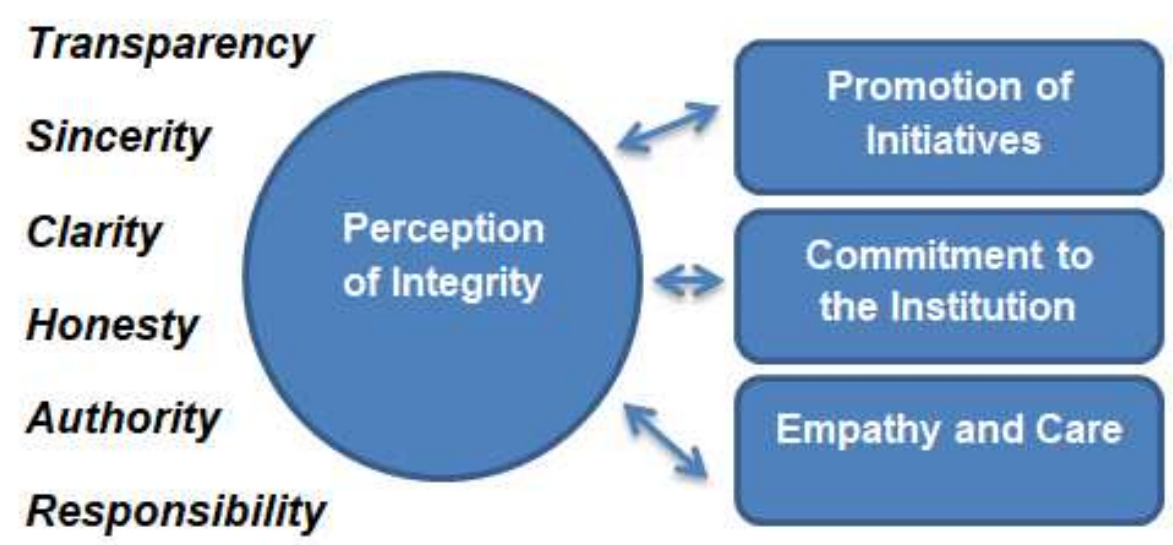

